$5-2002$

\title{
Using TIMSS to Inform Policy and Practice at the Local Level
}

Deborah Nelson

Follow this and additional works at: https://repository.upenn.edu/cpre_policybriefs

Part of the Curriculum and Instruction Commons, Educational Assessment, Evaluation, and Research Commons, Education Policy Commons, International and Comparative Education Commons, and the Science and Mathematics Education Commons

\section{Recommended Citation}

Nelson, Deborah. (2002). Using TIMSS to Inform Policy and Practice at the Local Level. CPRE Policy Briefs.

Retrieved from https://repository.upenn.edu/cpre_policybriefs/24

View on the CPRE website.

This paper is posted at ScholarlyCommons. https://repository.upenn.edu/cpre_policybriefs/24

For more information, please contact repository@pobox.upenn.edu. 


\title{
Using TIMSS to Inform Policy and Practice at the Local Level
}

\begin{abstract}
The Third International Mathematics and Science Study (TIMSS)-1995 and its successor, TIMSS-1999, provide education researchers, policymakers, and practitioners with rich, comparative data designed to help better understand the performance of educational systems. As such, TIMSS is a valuable tool in current efforts to improve mathematics and science instruction and to educate students in the United States to global standards of excellence. What can we learn from this ambitious and unprecedented international effort to provide meaningful, useful data for the reform of mathematics and science instruction? It is important to reflect on this question as we assess the promise and challenges of using TIMSS-type data in particular, as well as the broader national effort to use data to guide school improvement in general.
\end{abstract}

The first in CPRE's series of Policy Briefs about TIMSS (Dunson, 2000) looked at initial efforts to make use of TIMSS-1995 data. In this Policy Brief, we take a closer look at the ways in which TIMSS-1995 and TIMSS-1999 data have helped to inform changes in policy and practice as schools, districts, and states respond to the call for improvement in mathematics and science achievement. This Policy Brief was prepared to complement CPRE's effort to address this question in a TIMSS Policy Forum, held in Washington, DC, in May 2002. This forum convened TIMSS Benchmarking jurisdiction representatives, teachers, administrators, policymakers, researchers, and technical assistance providers to share successful strategies and ongoing challenges in taking full advantage of TIMSS data.

This Policy Brief is based primarily on data collected in structured interviews with Using TIMSS to Inform Policy and Practice at the Local Level By Deborah I. Nelson administrators and teachers in 10 TIMSS Benchmarking jurisdictions (referred to as "Benchmarkers"). These jurisdictions within the United States participated in the TIMSS- 1999 Benchmarking Study, committing their own resources and time in order to receive data from a representative sample of their own eighth-grade students. TIMSS Benchmarkers thus have international comparative data on their students' achievement and their system variables. Our purposive sample included equal representation from states, districts, and consortia with a variety of demographic characteristics. While TIMSS data have been used nationwide, Benchmarking jurisdictions are notable for their existing commitment to reform of mathematics and science programs and for the fact that they have access to their own local TIMSS- 1999 data.

This Brief is designed to facilitate networking and continued learning from TIMSS; it focuses on Benchmarkers' experiences, but is relevant for anyone interested in using TIMSS to improve mathematics and science instruction. Strategies are reported in summary form. Actual TIMSS data and analysis are not discussed in detail, but related references are provided at the end of this Brief.

Disciplines

Curriculum and Instruction | Educational Assessment, Evaluation, and Research | Education Policy | International and Comparative Education I Science and Mathematics Education

\section{Comments}

View on the CPRE website. 


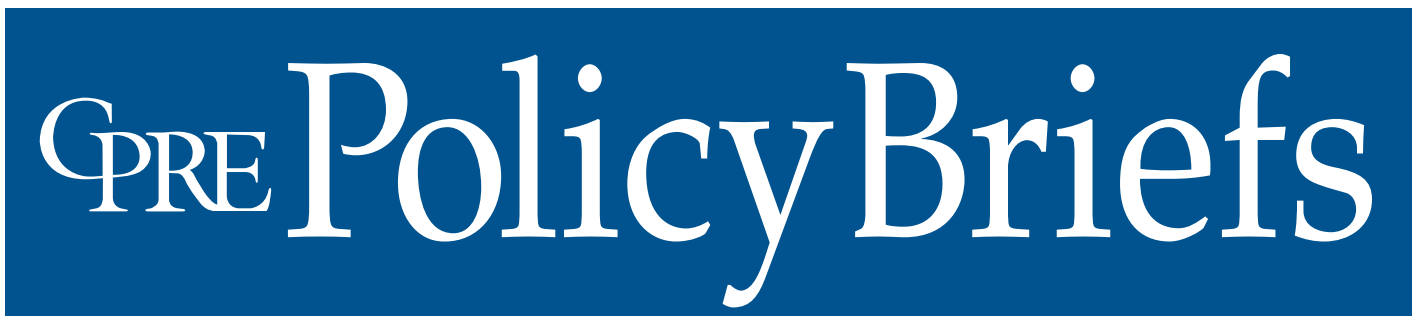

Reporting on Issues and Research in Education Policy and Finance

\section{Using TIMSS to Inform Policy and Practice at the Local Level}

By Deborah I. Nelson

The Third International Mathematics and Science Study (TIMSS)-1995 and its successor, TIMSS-1999, provide education researchers, policymakers, and practitioners with rich, comparative data designed to help better understand the performance of educational systems. ${ }^{1}$ As such, TIMSS is a valuable tool in current efforts to improve mathematics and science instruction and to educate students in the United States to global standards of excellence. What can we learn from this ambitious and unprecedented international effort to provide meaningful, useful data for the reform of mathematics and science instruction? It is important to reflect on this question as we assess the promise and challenges of using TIMSS-type data in particular, as well as the broader national effort to use data to guide school improvement in general.

The first in CPRE's series of Policy Briefs about TIMSS (Dunson, 2000) looked at initial efforts to make use of TIMSS-1995 data. In this Policy Brief, we take a closer look at the ways in which TIMSS-1995 and TIMSS-1999 data have helped to inform changes in policy and practice as schools, districts, and states respond to the call for improvement in mathematics and science achievement. This Policy Brief was prepared to complement CPRE's effort to address this question in a TIMSS Policy Forum, held in Washington, DC, in May 2002. This forum convened TIMSS Benchmarking jurisdiction representatives, teachers, administrators, policymakers, researchers, and technical assistance providers to share successful strategies and ongoing challenges in taking full advantage of TIMSS data.

This Policy Brief is based primarily on data collected in structured interviews with administrators and teachers in 10 TIMSS Benchmarking jurisdictions (referred to as "Benchmarkers"). These jurisdictions within the United States participated in the TIMSS$1999^{2}$ Benchmarking Study, committing their own resources and time in order to receive data from a representative sample of their own eighth-grade students. TIMSS Benchmarkers thus have international comparative data on their students' achievement and their system variables. Our purposive sample included equal representation from states, districts, and consortia with a variety of demographic characteristics. ${ }^{3}$ While TIMSS data have been used nationwide, Benchmarking jurisdictions are notable for their existing commitment to reform of mathematics and science programs and for the fact that they have access to their own local TIMSS1999 data.

This Brief is designed to facilitate networking and continued learning from TIMSS; it focuses on Benchmarkers' experiences, but is relevant for anyone interested in using TIMSS to improve mathematics and science instruction. Strategies are reported in summary form. Actual TIMSS data and analysis are not discussed in detail, but related references are provided at the end of this Brief.

\section{Background: What Do We Know About Using Data to Drive System and School Improvement?}

In the context of standards-based reform, data are critical tools in shaping school improvement efforts based on systematic use of evidence. Research has demonstrated great variability, however, in the ways that
May 2002

RB-36

Graduate School of

Education

University of

Pennsylvania

\section{Consortium for Policy Research in Education}

University of Pennsylvania

Harvard University

Stanford University

University of Michigan

University of Wisconsin-Madison 


\section{Policy Briefs}

data have driven reform in different contexts. Two broad factors shape this variability: 1 ) the nature and quality of the data, and 2) the capacities of systems to analyze and make use of data.

\section{Quality of Data}

Data can be seen as "scripts" that guide changes in policy and practice (Massell, 2001). The form and the content of data influence their use. Assessments, for example, vary in the populations they sample, the unit to which scores can be disaggregated, the content domains and skill sets assessed, the frequency and timing of data reporting, and the scaling of scores. These variations affect the way data are used to inform district- and school-level decision making and classroom instruction ( $\mathrm{O}^{\prime}$ Day, in press; Herman, in press).

TIMSS has a number of advantages as a tool for improvement. First, it was a rigorously executed international study and therefore has credibility for a variety of stakeholders looking to measure student achievement by global standards. Comparative international data allow educators to consult the policies and practices of higher achieving nations as possible strategies for reform. Also critical is the fact that TIMSS provides data not only on student achievement but on as many as 1,500 contextual variables that might help to explain variations in achievement. By supplementing assessment questions with student, teacher, and school questionnaires, videotaped lessons, and analyses of national curriculum frameworks, TIMSS is able to provide extensive data relevant to educational policy and practice. ${ }^{4}$

The many forms and broad dissemination $^{5}$ of TIMSS data helped gain attention from a variety of stakeholders: the highly publicized ranking of international student achievement lent urgency and credibility to existing critiques of mathematics and science instruction in the United States; TIMSSreleased items helped convince educators that the content and skills assessed were relevant to their students; the videotape data helped administrators, teachers, students, and the public to see concrete differences in lesson content and pedagogical style between American, German, and Japanese class-
CPRE is funded by the National Institute on Educational Governance, Finance, Policymaking, and Management; Office of Educational Research and Improvement; U.S. Department of Education. The research reported in this Brief was conducted by CPRE and funded under OERI Grant No. R215U980021308. Opinions expressed in this Brief are those of the author and do not necessarily reflect the views of the National Institute on Educational Governance, Finance, Policymaking, and Management; the Office of Educational Research and Improvement; the U.S. Department of Education; CPRE; or its institutional members.

rooms; and TIMSS analyses greatly increased the influence of the data by indicating clear, actionable alternatives for policy and practice - for example, the oft-repeated phrase from TIMSS researcher Bill Schmidt's studies that curricula in the United States are "a mile wide and an inch deep" (Schmidt, McKnight, \& Raizen, 1997).

Because TIMSS is not able to provide much of the information available from most state and local assessments - specifically data over time ${ }^{6}$ or disaggregated data - it should be viewed as a useful resource to be used in complement with these assessments and additional system data. Due to sampling procedures, TIMSS results cannot be disaggregated to particular units below the country or jurisdiction originally assessed; thus, TIMSS-1995 provides no local data ${ }^{7}$ and TIMSS-1999 cannot provide Benchmarkers with particular student, school, or, in the case of consortia, district data. In some cases these limitations presented significant challenges for use and interpretation, especially for those educators accustomed to the kind of particular school- and student-level data analysis prevalent in the context of current accountability policies.

\section{System Capacities}

While achievement data can do much to shed light on existing problems in student performance, they cannot offer explanations and solutions for these problems. Data will lead to improvements in student achievement only if states, districts, and schools have the capacity to analyze and use them. Research indicates that, in this respect, organizations vary greatly along a number of dimensions including: organizational needs and priorities, qualifications of personnel 
and technological expertise, existing capacity of teachers and administrators collectively to implement changes, and level of support for professional development (Massell, 2001; Abelmann \& Elmore, with Even, Kenyon, \& Marshall, 1999; O'Day, in press; Siskin, in press). Research indicates further that, in the case of schools, those with higher socioeconomic status and student achievement are more successful at taking advantage of data and resources than lower performing schools (Elmore, 2001; Siskin, in press).

Because of their amount and complexity, TIMSS-1999 Benchmarking data presented an even greater challenge for analysis and use than most assessment data. Benchmarkers had access to a number of external resources to help them in this task. All Benchmarkers were offered data analysis training by the International Study Center at Boston College and data analysis support through Michigan State University, funded by the National Science Foundation. In addition, a number of Benchmarkers, through their involvement with TIMSS, established ongoing relationships with researchers, universities, regional educational laboratories, other Benchmarkers, and national organizations such as the American Academy for the Advancement of Science (Project 2061, in particular), the National Science Foundation, and the National Goals Panel. Though some have been better able to access TIMSS-associated opportunities than others, all sampled Benchmarkers expressed great enthusiasm for the networking possibilities represented by TIMSS and a frustration at lack of sufficient time and resources to take full advantage of them.

\section{Benchmarkers' Experience Using TIMSS to Inform Policy and Practice at the Local Level}

\section{Setting the Agenda}

TIMSS data have been influential in both direct and indirect ways. In many cases, TIMSS data led directly to the formation of new initiatives such as Ohio's SMART (Science and Math Achievement Required for Tomorrow) Consortium, established explicitly to address mathematics and science achievement using higher standards, greater focus and rigor, and internationally competitive achievement goals. In other cases, TIMSS' influence was less direct, but, as many Benchmarking representatives indicated, there is little doubt that it has, over time, become part of the working language with which educators and the public think about mathematics and science instruction. As a representative from the Math and Science Collaborative $^{8}$ explained, "TIMSS informs virtually everything that we do in one way or another, either in very explicit conversations about TIMSS or in implicit ways, supporting the direction we are moving in."

\section{TIMSS Highlighted Issues for Reform}

Student Achievement. The majority of Benchmarkers looked at their own TIMSS1999 data primarily to compare student achievement in specific subtopics to other national and international jurisdictions. These results generally verified what Benchmarkers had learned from national analyses of TIMSS-1995 data and their own assessments of student achievement - that, for example, their students are weaker in physical science, inquiry, and measurement than their international peers. These results were not surprising for most, but they helped convince educators and the public that conclusions from national-level data had local relevance. In some cases, student achievement in certain subtopics was not as high as expected, leading to reform of existing programs. ${ }^{9}$ Many Benchmarkers also did comparisons of student achievement on specific released items; this was especially useful in helping mathematics and science leadership to think about results in relationship to their specific curricula.

Exploring Possible Relationships Between Contextual Variables and Achievement. TIMSS-1995 and TIMSS-1999 did more than focus attention on the need for reform they initiated a whole new level of discussions not possible with achievement data alone. TIMSS data raised questions about specific components of policy and practice, suggesting, most importantly, that concrete steps could be taken to improve instruction and increase achievement. 
Benchmarkers noted the strong influence of general messages emerging from analyses of contextual variables in TIMSS 1995 data specifically, the lack of curricular coherence and rigor in the United States, the need for increased focus on inquiry and problem solving, and the need to increase teachers' conceptual and pedagogical knowledge. While these initial findings did not indicate established relationships between the system variables mentioned and student achievement, they highlighted important differences between policies and practice in the United States and many high-achieving nations. ${ }^{10}$ This provided policymakers and practitioners with specific questions with which to approach reform of their mathematics and science programs.

Some messages emerging from analyses of TIMSS data have received more attention than others. For example, recent analyses have raised issues about content tracking and the role of socioeconomic factors in students' access to a rigorous curriculum. ${ }^{11}$ In order to address this issue, states, districts, and schools will need to look at a range of issues associated with course assignment, teacher assignment, professional development, and system incentives. While TIMSS data have highlighted this problem, it remains to be seen whether jurisdictions will take the comprehensive steps necessary to address it.

Several Benchmarkers have been able to complete more extensive analyses of their TIMSS-1999 data. These analyses were undertaken in cooperation with external partners such as Boston College, Michigan State University, and the North Central Regional Educational Laboratory. Benchmarkers engaged in these kinds of partnerships include SciMathMN, First in the World (FITW), Michigan Invitational Group, and the Math and Science Collaborative. These analyses examined the complex relationships between student achievement in mathematics and science and various educational inputs such as teaching practices, professional development, socioeconomic status, and student access to a rigorous curriculum. ${ }^{12}$

General messages emerging from TIMSS1995 data have thus far had a greater influence on shaping particular reform initiatives in our sampled Benchmarking jurisdictions than TIMSS-1999 Benchmarking data. This may be partly a function of the broader scope of the TIMSS-1995 data and the intense efforts related to its analysis and dissemination. It may also reflect the difficulty jurisdictions have had analyzing and acting on complex local data. In those jurisdictions that have recently completed extensive analyses of their TIMSS-1999 data, it is also too soon to know whether and how these analyses will impact policy and practice.

\section{Responding to TIMSS: Local Improvement Efforts}

TIMSS data raised questions primarily about what is taught and how it is taught. These questions led to reform efforts focused on curriculum and professional development. In this section, we review the changes to policy and practice implemented by Benchmarkers in their attempts to improve instruction and achievement. While TIMSS provided an excellent starting point, it could not offer comprehensive solutions. Benchmarkers combined TIMSS data with state and local assessment data and their knowledge of exemplary materials and best practices to craft appropriate solutions to TIMSS-generated questions. Benchmarkers' ability to use TIMSS data was thus influenced by their existing capacities to analyze and respond to data and take advantage of available resources.

\section{Developing and Revising Standards}

Several Benchmarkers used TIMSS-1995 data to launch their own projects aimed at providing mathematics and science content standards as a template for district curricular reform. For example, mathematics and science teachers and curriculum specialists participating in one of FITW's Teacher Learning Networks ${ }^{13}$ developed their own grade-level content standards after reviewing a complete TIMSS curriculum analysis, international and local curricula, and state standards. In addition, they consulted an analysis of national content standards and the curricula of two high-achieving TIMSS countries conducted by Mid-Continent Research for Education and Learning. ${ }^{14}$ 
TIMSS-1995 data were released and analyzed at a time when many state legislatures and departments of education were debating and implementing new content standards. In many cases these standards are quite broad in each subject area. Several Benchmarkers made use of TIMSS results in attempts to encourage more focused and rigorous content standards. The Math and Science Collaborative viewed the proposed Pennsylvania standards as "very much clay on the table" and were concerned that the standards should reflect lessons from TIMSS as well as national standards. They developed opportunities for educators to look at the proposed standards for rigor and coherence; findings from the resulting analysis were presented to the state. The Collaborative was also asked to testify before the State Senate when it was conducting a final review of science standards. The SMART Consortium used TIMSS to help in the development of Consortiumwide content standards. These standards were used as a resource by the Ohio Department of Education to inform its own mathematics and science standards.

\section{Curriculum Review}

Benchmarkers made extensive use of TIMSS data in evaluating and revising their mathematics and science curricula. General lessons from TIMSS-1995 national-level data, analysis of international curriculum variables, and information about their own students' strengths and weaknesses gave Benchmarkers a number of specific strategies and goals with which to approach these tasks. ${ }^{15}$ For some Benchmarkers, TIMSS findings prompted their first efforts to develop system-wide coherent and rigorous curricula.

FITW helped member districts to conduct their own curricular analyses. This effort was guided by use of the TIMSS General Topic Trace Map (GTTM), a framework consisting of 44 mathematics and 79 science topics (Schmidt, Raizen, Britton, Bianchi, \& Wolfe, 1997; Schmidt, McKnight, Cogan, Jakwerth, \& Houang, 1999). Using the GTTM, districts could assess the rigor and coherence of their curricula based on the breadth, duration, and flow of topics. ${ }^{16}$ Districts could use these analyses in conjunction with other data to raise important questions about their curricula. ${ }^{17}$ In one FITW district, for example, the
District Action Team used the results of the FITW curriculum analysis and its own assessments to make a general plan for curricular reform. This plan was referred to a mathematics and science curriculum committee composed of teachers, administrators, and central office staff, who revised the curriculum to make it more rigorous and coherent, especially in eighth-grade mathematics. They purchased new instructional materials to reflect these changes and are now in the process of implementing the new curriculum.

Naperville School District 203 also used the TIMSS data in development of their revised mathematics curriculum and are currently using it to inform revision of their science curriculum. In their recent revision of the mathematics curriculum, a curriculum committee looked at TIMSS-1995 videos, consulted research, and made use of lessons regarding the breadth and lack of depth and rigor of curricula in the United States. In response, they reduced the number of topics covered at each grade level and purchased multiple resources rather than single textbooks to implement the curriculum.

Teachers and administrators involved in curriculum reform efforts reported great benefits to their own understanding of content and pedagogy. One example comes from the Math and Science Collaboratives's Curriculum Framework Project. This project convened teacher-leaders from across the region to develop a framework that could be used by district teams of teachers and administrators in reforming their own curricula. Based on Schmidt's analysis of TIMSS curriculum variables, the project's goal was to ensure that the framework reflected international content standards and covered five-to-seven "big ideas" at each grade level. A participating teacher called this "the best professional development experience I've had in my whole career." After working on the framework, she used it in her own district to design a six-week curriculum reform effort in mathematics. Participants focused on articulating concepts and content across grade levels and developing performance assessments. With the Collaborative's help, participants later purchased materials to help them implement their new curricular goals. 


\section{Programs and Materials}

Benchmarkers mentioned lessons from TIMSS as a significant influence on their choice of curriculum materials. In efforts to focus on fewer topics in greater depth, many districts have purchased materials to accompany units or modules, either as a supplement or a replacement for textbooks. The Math and Science Collaborative provides support to districts in their selection of new materials by sponsoring workshops and maintaining a clearinghouse of exemplary materials that reflect rigorous national and international standards. Based on TIMSS findings, they began an initiative to encourage the use of these materials and greater curricular focus at the middle school level. As part of a separate initiative to enable all students to have access to rigorous curriculum at the high school level, they are also sponsoring implementation of the Cognitive Tutor Project, a curriculum program developed at Carnegie Mellon University. ${ }^{18}$

\section{Professional Development}

While Benchmarkers varied in the degree of professional development opportunities they sponsored, all acknowledged its critical role in building the capacity to both analyze and use TIMSS data. As a representative from FITW put it, "If you don't build the capacity, it makes no difference what the TIMSS data say; you're not going to get anywhere." Professional development efforts were generally focused on curriculum review, implementation of new curricula, or on issues of pedagogy raised by TIMSS analyses.

\section{Building District Capacity}

States and consortia recognized that instructional improvement hinges ultimately on local efforts. In most cases, districts are responsible for providing the kind of ongoing support necessary to help administrators and teachers make meaningful and lasting changes to school and classroom practice. Many professional development efforts therefore focused on helping district leadership teams think about how best to implement lessons from TIMSS.

The Math and Science Collaborative sponsored a Core Leadership Training for district teacher and administrator teams to use TIMSS data relevant to curriculum, instruction, and assessment as a tool for improving their mathematics and science programs. These teams looked at national and local TIMSS data and analyses and completed online challenges with TIMSSreleased items. They then identified important areas of action in their own districts and developed associated professional development plans. In one district, a participant developed a summer workshop for math and science teachers to expose them to important curriculum and pedagogy issues raised by TIMSS. Following this workshop, a Science Planning Group redeveloped the district's elementary science program, trimming content and increasing focus on student inquiry and problem solving. The team also developed associated performance assessments and replaced textbooks with exemplary materials that reflected the new curriculum. A Math Leadership Team developed a twoyear professional development program focused on helping teachers change their pedagogy away from simply teaching algorithms toward a more problem-solving approach.

In Minnesota, SciMathMN developed a series of workshops designed to help district leadership teams use data to make continuous improvements in their mathematics and science programs. In these workshops, they used Minnesota TIMSS data and TIMSS1995-related professional development materials $^{19}$ to help district administrators and teachers think about the kinds of questions raised by data and how these inquiries might lead to system improvement. For many districts, the data raised questions about curriculum sequences and materials; TIMSS data prompted conversations across grade levels that in some cases had never occurred. Others looked at pedagogical practices based on issues raised by analyses of TIMSS video data. ${ }^{20}$ The major challenge presented by these workshops was getting district leadership teams to take a comprehensive look at their mathematics and science programs rather than just focusing on one aspect such as pedagogical style or middle school curricula. Districts do not always have sufficient personnel or other resources to engage in this kind of comprehensive effort. 


\section{Building Teacher Capacity}

Shaping Teachers' Professional Development Options. A number of Benchmarkers are using TIMSS to guide the range of professional development experiences they provide for teachers. Based on data demonstrating the relative weakness of teachers' content knowledge in the United States compared to the content knowledge of teachers in highachieving nations, they are increasing the number of content-related professional development opportunities for teachers. These can take the form of summer institutes, graduate courses, or school-based support from content specialists. Other TIMSS-related professional development offerings address pedagogical strategies related to teaching for understanding and inquiry-based learning.

The SMART Consortium, for example, has developed a range of professional development offerings that can be used by districts to help teachers implement new curricula and improve their pedagogical techniques. Responding to their own TIMSS data which suggested a relationship between teachers' content knowledge and student achievement, they also developed a series of contentfocused summer institutes for teachers. To assess the need for this initiative, they supplemented their TIMSS data by developing an additional instrument to measure teacher content knowledge.

Lesson Study. Analysis of TIMSS videotape data presented in Stigler and Hiebert's (1999) widely disseminated book, The Teaching Gap: Best Ideas From the World's Teachers for Improving Education in the Classroom, has focused attention on the great need to support development of teachers' knowledge and practice. Their analysis found, in particular, that teachers in the United States focus their instruction less on developing students' conceptual understanding than do Japanese and German teachers. They also described "lesson study," a routine component of professional practice in Japan, as a powerful means to help teachers develop this capacity. Teachers engaging in lesson study plan collaboratively, observe, and critique lessons designed to address particular areas of common curricular concern. ${ }^{21}$

Use of lesson study does not follow directly from TIMSS data; it is, however, a practice used by one of the highest achieving TIMSS nations to help teachers develop pedagogical skills that TIMSS data suggest are important. As such, it provides an interesting example of the way comparative studies can provide insights into other ways of approaching teaching and learning. ${ }^{22}$ Districts and schools across the country, as well as a number of Benchmarking jurisdictions, have begun to implement lesson study as part of their professional development programs.

Augmenting Existing Initiatives. In many cases, Benchmarkers' efforts to analyze data and reform curricula are directly linked with their existing strategies to build professional capacity at all levels. For example, Naperville's extensive use of data is facilitated by its historic and continuing commitment to professional development and collaborative decision making. Curriculum revision in Naperville is undertaken by 40 -member curriculum committees that follow seven-year cycles of review, development, and implementation. These committees include teacher representatives from every school in the district. Leadership teams within these committees are given extra support by the district to develop their knowledge of research, reform strategies, and available curriculum materials. They are sent to national, state, and local conferences and given release time within the school year to examine research and best practices. During the implementation phase of a revised curriculum, all system teachers attend a curriculum workshop in the summer and are provided with release time during the school year to develop collaborative units, attend grade-level meetings, and participate in continuing professional development opportunities.

The Delaware Science Coalition and Miami-Dade County incorporated TIMSS results in the extensive site-based professional development support systems they had established, supported largely by grants from the National Science Foundation. In MiamiDade County, educational specialists working in the district's Urban Systemic Program use a TIMSS-derived curriculum mapping process (as described above in relationship to FITW) to help teachers and administrators make data-driven decisions using their state science assessment. In Delaware, the Local 
Systemic Change Initiative involves educators across the state in a collaborative process for reviewing curriculum, selecting instructional units, purchasing or developing materials, providing associated professional development opportunities, and developing assessments. Influenced partly by TIMSS data, Leadership Teams have chosen to emphasize inquiry-based learning and to focus on fewer topics in greater depth. ${ }^{23}$

\section{Evaluating Efforts}

TIMSS is clearly a useful tool in guiding reforms according to international standards of achievement and instruction, but it is as yet unclear whether and how TIMSSinspired reforms achieve their goals. As reported above, TIMSS has been used widely to highlight important issues and to suggest practices that may be successful in improving mathematics and science programs. As with any use of data to drive reform, these are important first steps but do not ensure system improvement. It is critical that states and districts rigorously evaluate the impact of their reforms using indicators that provide valid and continuous data on larger system goals. State and local assessments vary in their ability to measure progress according to the international standards represented by TIMSS and, in some cases, comprehensive assessment programs in mathematics and science have yet to be implemented. Further, TIMSS raises questions about the quality of curriculum and instruction that cannot be answered by assessment data alone.

\section{Assessments}

In the context of standards-based reform, assessments aligned with learning standards and achievement goals are a critical component of effective evaluation. TIMSS has been used by a number of Benchmarkers as a tool with which to examine state and district assessments for appropriate content and scaling. For example, the Delaware Science Coalition has made extensive use of TIMSS in ensuring that Delaware's state test, the Delaware Student Testing Program (DSTP), is aligned with international standards. The Coalition is also using TIMSS in a project designed to make a conceptual framework of Delaware's science achievement and assess whether the DSTP is measuring what they want it to measure. Initial results indicate a greater need to focus on problem solving over data retrieval skills. Academy School District \#20 in Colorado was able to use its TIMSS results to put student achievement in mathematics on the Colorado Student Assessment Program (CSAP) in context. Scaling on the CSAP indicated that only $25 \%$ of their students had achieved a proficient rating, whereas results from TIMSS-1999 indicated that their students were in the top quartile of TIMSS-1999 nations and jurisdictions.

In most cases, state assessments get more attention from districts and schools than TIMSS as they are directly linked with accountability systems and consequences. When these tests are aligned in form and content with TIMSS, they can be effective tools to measure progress toward TIMSS-inspired system goals. When the tests differ significantly from TIMSS, however, systems that implement them in conjunction with TIMSSinspired reforms may be sending conflicting messages to educators. In one district, for example, there is significant pressure to perform well on the state science assessment which covers a broad range of topics at each grade level. This makes it difficult to focus in depth on fewer topics as do the higher achieving TIMSS nations. In one state, legislators recognized the importance of raising mathematics achievement to global standards yet voted to implement a graduation test that focused more on low-end basic skills than the more rigorous content tested in TIMSS. It can also be difficult for district personnel to focus on lessons learned from TIMSS in the face of constant and increasing demands from state and district assessments. In one mid-sized district, for example, a single person is responsible for coordinating district activity around curriculum, professional development, and a full battery of state and district assessments in science.

\section{Additional Indicators}

Many Benchmarkers recognized the need for additional data to inform their decision making and to monitor progress toward achieving system goals. The Math and Science Collaborative, for example, created District Learning Profiles that record the percentage of graduating seniors that have had success in key gateway courses such as Alge- 
bra I and upper-level math and science courses. They are also helping districts to use a number of additional tools such as in-class and performance assessments to inform and monitor their improvement efforts. FITW physics teachers launched their own study following lower-than-expected results in the TIMSS 12th-grade physics exam. These teachers reviewed TIMSS results as well as their own curricular and instructional practices. They supplemented their existing knowledge about teachers' beliefs and attitudes by giving the TIMSS teacher survey to a sample of high school teachers (only fourthand eighth-grade teachers were included in the original survey). ${ }^{24}$

In cooperation with the United States TIMSS National Research Center at Michigan State University, one county in Michigan is currently using TIMSS methodology to collect extensive data on its own student achievement and curriculum variables. Going beyond TIMSS-1995 and TIMSS-1999 studies, they are testing every student in grades 3-12, and administering a modified version of the teacher questionnaire. Analysis of these data will be a first step toward reform of their mathematics and science programs. A major goal of their analysis will be exploration of the relationship between cohort achievement growth and curriculum. ${ }^{25}$

\section{Conclusion}

The TIMSS experience substantially broadened what was described by many Benchmarkers as their previous, isolated efforts at reform. Comparative achievement data allowed jurisdictions to rank their performance by global standards and to look to high-achieving nations and Benchmarkers for examples of policies and practices that might account for student success, while contextual variables provided broad conclusions about the particular practices of higher achieving nations. TIMSS has thus been a critical tool in highlighting important areas of reform. However, it offers no panaceas guaranteed to be effective across contexts and over time. The continuing effectiveness of TIMSS-inspired reforms hinges ultimately on the ability of states, districts, and schools to craft local solutions and to evaluate and refine their efforts.
Comprehensive, effective use of TIMSS data requires coordinated attention to issues of curriculum, assessment, instructional materials, professional development, teacher qualifications, and student access to rigorous curriculum, among others. Capacity to address these issues varied between Benchmarking jurisdictions as well as within different components of these jurisdictions. Benchmarkers with existing personnel and infrastructure devoted to these issues were better situated to take advantage of TIMSS data than others. Capacity varied within jurisdictions as well: within states and consortia, for example, some districts had greater existing system resources than others; many Benchmarkers mentioned the greater difficulty of implementing TIMSS-related changes at the high school level, in keeping with their existing difficulties influencing instruction in high schools. These differences reinforce emerging questions about whether and how data-driven strategies for reform can help to increase performance in low-performing schools and systems; unless data are accompanied by efforts to build capacity for their analysis and use, they may be unlikely to address differences in student achievement resulting from existing differences in system capacities.

TIMSS has clearly succeeded in both focusing attention on and guiding improvement of mathematics and science instruction in many Benchmarking jurisdictions. Benchmarkers' experience illustrates the important role that rich, comparative data can play in reform efforts; it also indicates the limited power of data in the absence of system capacity to analyze them and to craft, implement, and evaluate reforms. In learning from the TIMSS experience, it is thus important to consider the particular qualities of the TIMSS data as well as the factors that have contributed to Benchmarkers' ability to analyze and use them.

\section{About the Author}

Deborah Nelson is a research assistant at CPRE where she has worked on issues related to districts' use of data and policymakers' use of educational research. She is currently conducting research on district policies related to professional development and instructional improvement. 


\section{Policy Briefs}

\section{End Notes}

1. In this Policy Brief, "TIMSS" refers to both TIMSS-1995 and TIMSS-1999. For an overview of TIMSS-1995 and TIMSS-1999 data collection and results, consult: http://nces.ed.gov/timss. While both TIMSS-1995 and TIMSS-1999 provide international comparative student achievement data as well as information on numerous contextual variables, they differ from each other in several ways. Differences relevant for this discussion include: 1) TIMSS-1995 collected data on student achievement in the fourth and eighth grades and the final year of secondary school whereas TIMSS-1999 collected data only in the eighth grade; and 2) the TIMSS-1999 Benchmarking study allowed jurisdictions within the United States to participate independently.

2. Two jurisdictions participated in extensions of the TIMSS-1995 data collection.

3. Jurisdictions were also chosen based on stated commitment to using TIMSS data. Our sample is therefore not necessarily representative of all Benchmarkers' experiences.

4. For more information on these contextual variables and the TIMSS data collection in general, consult http://timss.bc.edu/ TIMSS1/about_main.html.

5. A number of reports supported TIMSS data dissemination. These include: summary reports by the National Center for Education Statistics, detailed descriptive analyses by the International Study Center at Boston College, analyses of curriculum variables by the TIMSS Resource Center at Michigan State University, and analyses of videotape data by LessonLab at the University of California at Los Angeles. Associated materials such as the TIMSS Resource Kit (Office of Educational Research and Improvement, 1999) highlighted major TIMSS findings and provided tools for local reform.

6. Each provide a limited amount of data over time. TIMSS-1995 tested representative samples of third- and fourth-grade and seventh- and eighth-grade students. TIMSS-1999 tested a cross-sectional sampling of eighthgrade students four years after a cross-sectional sampling of fourth-grade students were tested. In addition, the First in the World (FITW) Consortium has collected two sets of data, one as a TIMSS follow-up in 1996 and one in TIMSS-1999.

7. Several jurisdictions, including Minnesota and FITW, used TIMSS-1995 methodology to collect their own data.

8. The Math and Science Collaborative is the organization that sponsored participation of the Southwest Pennsylvania Consortium in the TIMSS-1999 Benchmarking Study.

9. See, for example, the evaluation of high school physics undertaken by FITW physics teachers explained later in this Brief.

10. These relationships have since been more fully explored in Schmidt (2001).

11. See, for example, Schmidt, Kogan, and Wiley (2002) and the analysis of Southwest Pennsylvania data at http://www.msc.collaboratives.org.

12. For more details about these analyses consult the following web sites:

The Math and Science Collaborative: http:/ / www.msc.collaboratives.org

First in the World: http://www.ncrel. org/re/ae2

SciMathMN: http://www.negp.gov/ reports/mntimss.pdf

Michigan Invitational Group: http:// mathematicallysane.com/evidence/mig.asp.

13. Teacher Learning Networks are at the core of FITW's overall strategy of building an inter-district learning community. For more information about these networks, see www.ncrel.org/re/tlnr.

14. To find out more about FITW's standards project, consult http://www.ncrel. org/re/fitwsp/.

15. Some Benchmarkers are also making use of the TIMSS 2003 Assessment Frameworks and Specifications. These are available at http://isc.bc.edu/timss2003i/framework.html

16. The working manual is available at http:/ / www.ncrel.org/re/gttmr.

17. This process of curriculum analysis is detailed in North Central Regional Educational Laboratory (2002). An associated tool for curriculum analysis can be accessed at www.ncrel.org/currmap. 
18. For information about this program, consult http:// www.carnegielearning.com.

19. For example, National Research Council (1999).

20. The most common resource in this effort is Stigler and Hiebert (1999). Frequent use is also made of released videotape data. Information available at http://nces.ed.gov/ timss/timss95/video.asp

21. In addition to Stigler and Hiebert's work, a number of scholars have helped to explain and popularize lesson study in the United States. See the references at the end of this Brief.

22. Another example, not described in this Brief, is the use of Singapore's Mathematics Textbooks.

23. This initiative first focused on elementary science but has expanded to include K12 mathematics and science.

24. For additional information on this project, consult http://www.ed.gov/pubs/ FirstLook/ImproveMath.html

25 . At the time of publication, results from this analysis were not yet available. For additional information, contact the U.S. TIMSS National Research Center at http:// ustimss.msu.edu.

\section{References}

Abelmann, C., \& Elmore, R. F., with Even, J., Kenyon, S., \& Marshall, J. (1999). When accountability knocks, will anyone answer? (CPRE Research Report No. RR-042). Philadelphia: Consortium for Policy Research in Education, University of Pennsylvania.

Dunson, M. (2000). From research to practice and back again: TIMSS as a tool for educational improvement (CPRE Policy Brief No. RB-30). Philadelphia: Consortium for Policy Research in Education, University of Pennsylvania.

Elmore, R. F. (2001, April) Psychiatrists and lightbulbs: Educational accountability and the problem of capacity. Paper presented at the annual meeting of the American Educational Research Association, Seattle, WA.
Herman, J. (in press). Instructional effects in elementary schools. In S. H. Fuhrman \& R. F. Elmore (Eds.), Redesigning accountability systems. New York: Teachers College Press.

Massell, D. (2001). The theory and practice of using data to build capacity: State and local strategies and their effects. In S. H. Fuhrman (Ed.), From the capitol to the classroom: Standards-based reform in the states (pp. 148-169). Chicago: University of Chicago Press, National Society for the Study of Education.

National Research Council. (1999). Global perspectives for local action: Using TIMSS to improve U.S. mathematics and science education. Washington, DC: National Academy Press.

North Central Regional Educational Laboratory (2002). Learning from TIMSS 1999: A guidebook for using TIMSS 1999 data for local school improvement. Naperville, IL: Author.

O'Day, J. A. (in press). Complexity, accountability, and school improvement. In S. H. Fuhrman \& R. F. Elmore (Eds.), Redesigning accountability systems. New York: Teachers College Press.

Office of Educational Research and Improvement. (1999). Attaining excellence: A TIMSS resource kit. Washington, DC: Author.

Schmidt, W. H. (2001). Why schools matter: A cross-national comparison of curriculum and learning. San Francisco: Jossey Bass.

Schmidt, W. H., Kogan, L., \& Wiley, D. (2002). Who takes what math and in which track?: Using TIMSS to characterize United States students' eighth-grade mathematics learning opportunities. Educational Evaluation and Policy Analysis, 23(4).

Schmidt, W. H., McKnight, C. C., Cogan, L. S., Jakwerth, P. M., \& Houang, R. T. (1999). Facing the consequences: Using TIMSS for a closer look at United States mathematics and science education. Boston: Kluwer Academic Publishers.

Schmidt, W. H., McKnight, C. C., \& Raizen, S. A. (1997). A splintered vision: An investigation of U.S. science and mathematics education. Boston: Kluwer Academic Publishers. 
Schmidt, W. H., Raizen, S. A., Britton, E. D., Bianchi, L. J., \& Wolfe, R. G.(1997). Many visions, many aims: A cross-national investigation of curricular intentions in school science. Boston: Kluwer Academic Publishers.

Siskin, L. (in press). The challenge of the high schools. In S. H. Fuhrman \& R. F. Elmore (Eds.), Redesigning accountability systems. New York: Teachers College Press.

Stigler, J. W., \& Hiebert, J. (1999). The teaching gap: Best ideas from the world's teachers for improving education in the classroom. New York: The Free Press.

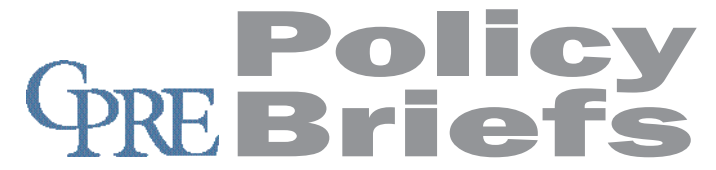

Graduate School of Education

University of Pennsylvania

3440 Market Street, Suite 560

Philadelphia, PA 19104-3325

\section{About CPRE}

The Consortium for Policy Research in Education (CPRE) studies alternative approaches to education reform in order to determine how state and local policies can promote student learning. Currently, CPRE's work is focusing on accountability policies, efforts to build capacity at various levels within the education system, methods of allocating resources and compensating teachers, governance changes like charters and mayoral takeovers, finance, student and teacher standards, and student incentives. The results of this research are shared with policymakers, educators, and other interested individuals and organizations in order to promote improvements in policy design and implementation.

CPRE unites five of the nation's leading research institutions to improve elementary and secondary education through research on policy, finance, school reform, and school governance. Members of CPRE are the University of Pennsylvania, Harvard University, Stanford University, the University of Michigan, and the University of Wisconsin-Madison.

CPRE Policy Briefs are published by CPRE. To learn more about CPRE research or publications, please call 215-573-0700 or access CPRE publications at www.cpre.org; www.wcer.wisc.edu/cpre/; or www.sii.soe.umich.edu. 


\section{Additional TIMSS-related Resources}

\section{General}

International Study Center at Boston College TIMSS Homepage: http://timss.bc.edu/

National Center for Education Statistics TIMSS Homepage: http://nces.ed.gov/timss/

National Research Council. (1999). Global perspectives for local action: Using TIMSS to improve U.S. mathematics and science education. Washington, DC: National Academy Press.

\section{Curriculum}

Curriculum mapping tool developed by the TIMSS National Research Center and the North Central Regional Educational Laboratory: http://currmap.ncrel.org/default.htm

TIMSS 2003 Assessment Frameworks and Specifications: http:/ /isc.bc.edu/timss2003i/framework.html

U.S. TIMSS National Research Center at Michigan State University Homepage: http://ustimss.msu.edu/.

\section{Videotape Study}

Lesson Lab at the University of California-Los Angeles: http://www.lessonlab.com/index.htm

Stigler, J. W, \& Hiebert, J. (1999). The teaching gap: Best ideas from the world's teachers for improving education in the classroom. New York: Free Press.

TIMSS 1995 Video Study Homepage: http:/ /nces.ed.gov/timss/timss95/video.asp

\section{Lesson Study}

Lesson Study Research Group at Columbia University Teachers' College: http:/ /www.tc.columbia.edu/lessonstudy/

Lewis, C., \& Tsuchida, I. (1998). A lesson is like a swiftly flowing river: Research lessons and the improvement of Japanese education. American Educator, Winter, 14-17 \& 50-52.

Research for Better Schools lesson study resource guide: http://www.rbs.org/lesson_study/index.shtml

Yoshida, M. (1999). Lesson study [Jugyokenkyu] in elementary school mathematics in Japan: A case study. Paper presented at the annual meeting of the American Educational Research Association, Montreal, Canada. 


\section{Benchmarking Jurisdictions}

The following 10 Benchmarking Jurisdictions were contacted for this study:

Academy School District \#20

7610 North Union Boulevard

Colorado Springs, CO 80920

Contact: Alisabeth Hohn

Phone: (719) 598-9534

E-mail: ahohn@d20.co.edu

Delaware Science Coalition

Delaware Foundation for Science and Mathematics

Education

Room 1115, Community Service Building

100 West 10th Street

Wilmington, DE 19801

Contact: Jack Collette

Phone: (302) 397-0034

E-mail: jackcollette@dca.net

First in the World Consortium

1250 Sanders Road

Northbrook, IL 60062

Contact: David Kroeze

Phone: (847) 498-2610

E-mail: kroeze.d@northbrook27.k12.il.us

Math and Science Collaborative (Southwest Pennsylvania Consortium)

2650 Regional Enterprise Tower

425 Sixth Avenue

Pittsburgh, PA 15219

Contact: Nancy Bunt

Phone: (412) 201-7404

E-mail: buntn@collaboratives.org

Miami-Dade County Public Schools

1500 Biscayne Boulevard

Suite 327-T

Miami, FL 33132

Contact: Kathryn Carr

Phone: (305) 995-1916

E-mail: kcarr@sbab.dade.k12.fl.us
Missouri

Missouri Department of Education

205 Jefferson Street

P.O. Box 480

Jefferson City, MO 65102-0480

Contact: James Friedebach

Phone: (573) 751-1395

E-mail: jfriedeb@mail.dese.state.mo.us

Naperville Community School District 203

203 Hillside Road

Naperville, IL 60540

Contact: Jodi Wirt

Phone: (630) 420-6319

E-mail: jwirt@ncusd203.org

Rochester City School District

131 West Broad Street

Rochester, NY 14614

Contact: Michael Chan

Phone: (716) 262-8135

E-mail: michael.chan@rcsd-k12.org

SciMathMN

1500 Highway 36 West

Roseville, MN 55113-4266

Contact: Bill Linder-Scholer

Phone: (651) 582-8813

E-mail: bill.linder-scholer@state.mn.us

Project SMART Consortium

22800 Cedar Point Road

Cleveland, OH 44142

Contact: Terry Krivak

Phone: (440) 962-3094

E-mail: terrykrivak@oai.org 